\title{
First camera-trap record of the snow leopard Panthera uncia in Gaurishankar Conservation Area, Nepal
}

\author{
Narayan Prasad Koju, Bijay Bashyal, Bishnu Prasad Pandey \\ Satya Narayan Shah, Shankar Thami and William V. Bleisch
}

\begin{abstract}
The snow leopard Panthera uncia is the flagship species of the high mountains of the Himalayas. There is potentially continuous habitat for the snow leopard along the northern border of Nepal, but there is a gap in information about the snow leopard in Gaurishankar Conservation Area. Previous spatial analysis has suggested that the Lamabagar area in this Conservation Area could serve as a transboundary corridor for snow leopards, and that the area may connect local populations, creating a metapopulation. However, there has been no visual confirmation of the species in Lamabagar. We set 11 infrared camera traps for 7 months in Lapchi Village of Gaurishankar Conservation Area, where blue sheep Pseudois nayaur, musk deer Moschus leucogaster and Himalayan tahr Hemitragus jemlahicus, all snow leopard prey species, had been observed. In November 2018 at 4,100 m, $5 \mathrm{~km}$ south-west of Lapchi Village, one camera recorded three images of a snow leopard, the first photographic evidence of the species in the Conservation Area. Sixteen other species of mammals were also recorded. Camera-trap records and sightings indicated a high abundance of Himalayan tahr, blue sheep and musk deer. Lapchi Village may be a potentially important corridor for snow leopard movement between the east and west of Nepal and northwards to Quomolongma National Park in China. However, plans for development in the region present increasing threats to this corridor. We recommend development of a transboundary conservation strategy for snow leopard conservation in this region, with participation of Nepal, China and international agencies.
\end{abstract}

Narayan Prasad Koju* (Corresponding author, (1) orcid.org/0000-0002-43030520) Center for Post Graduate Studies, Nepal Engineering College, Lalitpur, Nepal. E-mail npkoju.2003@gmail.com

BiJAY BASHYAL (10) orcid.org/0000-0002-5745-4762) Central Department of Environmental Science, Tribhuvan University, Kathmandu, Nepal

Bishnu Prasad Pandey, Satya Narayan Shah (10 orcid.org/0000-0003-46771866) and Shankar Thami Gaurishankar Conservation Area, National Trust of Nature Conservation, Kathmandu, Nepal

WiLliam V. BLeISCH (10 orcid.org/0000-0001-6549-5823) China Exploration and Research Society, Hong Kong

${ }^{*}$ Also at: Naaya Aayam Multi-disciplinary Institute, Kathmandu, Nepal, Department of Psychology, University of Washington, Seattle, USA, and Central Department of Environmental Science, Tribhuvan University, Kathmandu, Nepal

Received 19 June 2019. Revision requested 10 September 2019.

Accepted 9 January 2020. First published online 14 October 2020.
Keywords Camera trap, corridor, Gaurishankar Conservation Area, Nepal, Panthera uncia, prey abundance, transboundary, snow leopard

Supplementary material for this article is available at doi.org/10.1017/So03060532000006X

The charismatic snow leopard Panthera uncia, the flagI ship species of the high mountains of Asia, is categorized as Vulnerable on the IUCN Red List (Jackson, 1979b; McCarthy et al., 2017). It is an apex predator in the Himalayas and an indicator of a healthy montane ecosystem (MoFSC, 2017). Snow leopards range along the northern frontier of Nepal (McCarthy \& Chapron, 2003) and the country is believed to harbour 300-500 individuals, making it a key range country (WWF, 2018). In Nepal the snow leopard has been reported in Annapurna Conservation Area, Shey Phoksundo National Park, Kangchenjunga Conservation Area, Manaslu Conservation Area, Makalu Barun National Park, Dhorpatan Hunting Reserve, Sagarmatha National Park (Jackson, 1979a,b; Green, 1988; McCarthy \& Chapron, 2003; WWF, 2018), Langtang National Park (Kyes \& Chalise, 2005; WWF, 2018) and Api Nampa Conservation Area (Khanal et al., 2020).

Even though potential habitat for the snow leopard is continuous from east to west along the Himalayan range, studies on the species have been limited to Kanchanjunga and the Mt Everest region in the eastern Himalayas, Manang and Mustang in the central Himalayas, and Humla, Dolpa and Mugu in the western Himalayas. An estimated 39 snow leopards inhabit the eastern Himalayas of Nepal (from Kanchanjunga Conservation Area to Langtang National Park; WWF, 2012). There is a gap in information about the status of the snow leopard in Gaurishankar Conservation Area, part of the eastern Himalayas and potentially a key site for the species, as it connects Langtang National Park to the west and Sagarmatha National Park to the east with the larger contiguous Tibetan plateau to the north (Fig. 1). Ale et al. (2010) reported the presence of the snow leopard in Rolwaling area (c. $35 \mathrm{~km}$ south-west of Lapchi Village) in Gaurishankar Conservation Area, based on indirect signs (pugmarks, hair and faeces). Forrest et al. (2017), based on spatial analysis, suggested that the Lamabagar area in Gaurishankar Conservation Area may serve as a transboundary corridor for the snow leopard, 


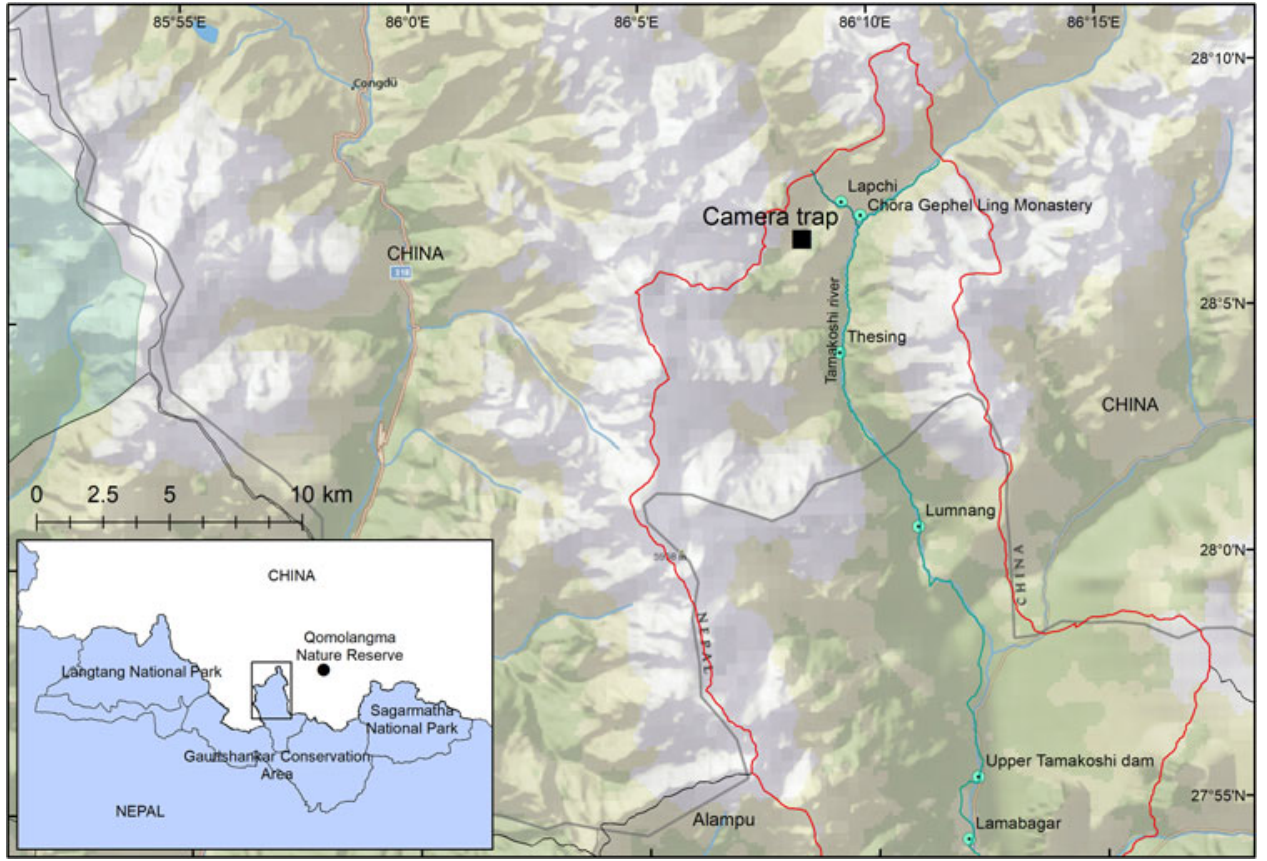

FIG. 1 The study area, with Lapchi valley in Lamabagar and the location of the camera trap that recorded a snow leopard Panthera uncia in November 2018. hypothesizing that the area could connect local populations of snow leopards, creating a metapopulation. MoFSC (2017) speculated about the possible presence of the snow leopard in Lapchi Village in Lamabagar.

We conducted this study to assess the distribution and activity patterns of wildlife in Lapchi Village in the climatically diverse Gaurishankar Conservation Area (MoFSC, 2017; Sindorf, 2017). This landscape comprises subtropical to nival bioclimatic zones, with 16 vegetation types and a reported faunal diversity of 235 bird, 34 mammal, 16 fish, 14 snake, 10 amphibian and eight lizard species (NTNC, 2013). The Conservation Area comprises six blocks: Gumba, Lamabagar/Lapchi, Rolwaling, Bigu/Kalinchowk, MarbuKhare and Gumdel/Marbu (NTNC, 2013). Lapchi Village (formerly in Lamabagar Village Development Committee, which is now subsumed in Bigu Rural Municipality) is bounded by the border with China to the east, west and north, at the foot of the Lapchi Khang mountain range, which is an important pilgrimage destination for Tibetan Buddhists and is known for the meditation caves of the Tibetan saint and poet, Jetsun Milarepa. The caves surround the main monastery of Lapchi, Chöra Gephel Ling.

We set 11 infrared camera traps in the $32 \mathrm{~km}^{2}$ Lapchi Village for 7 months, during 22 October 2018-6 April 2019 (188 days), at a minimum of $2 \mathrm{~km}$ apart in randomly selected $2 \times 2 \mathrm{~km}$ grid squares. We set three of the cameras above 4,000 $\mathrm{m}$ altitude near a possible snow leopard scat and the carcass of a blue sheep Pseudois nayaur, aiming to record movement of ungulates and snow leopards in the Lamabagar corridor below. These three cameras were installed in moraines with sparse vegetation of alpine grasses and patches of shrubs such as Rhododendron anthopogon and juniper Juniperus sp. This is an area of steep canyons above an alpine stream, surrounded by broken terrain of cliffs, scree slopes and rocky outcrops, covered by snow when we set the cameras.

We set two types of Bushnell Trophy Camera (Bushnell, Overland Park, USA): Model \#119537C, set in hybrid mode, to take photographs and videos simultaneously, and Model \#119405C, to take photographs only. Cameras were set to run continuously, with a time interval of one second between triggers and three shots per trigger. Of the 11 cameras, we lost two to theft, one from near the border with China and one from pasture near the village.

During installation of the cameras we observed individual musk deer Moschus leucogaster and multiple groups of blue sheep (Supplementary Plate 1) and Himalayan tahr Hemitragus jemlahicus, and also the possible scat of a snow leopard (Supplementary Plate 2) and carcasses of blue sheep possibly predated by a snow leopard (Supplementary Plate 3 ). Camera-trap records and direct sightings indicated a high abundance of Himalayan tahr, blue sheep and musk deer, suitable prey for the snow leopard. During installation and recovery of the cameras we observed a minimum of seven musk deer, three herds of blue sheep and multiple herds of Himalayan tahr around the area where the image of a snow leopard was later captured. The three herds of blue sheep comprised a minimum of 46 individuals. The cameras recorded 83 events of musk deer and 52 events of Himalayan tahr (an event is a series of images separated by more than 1 hour from other events); 17 species of mammals were recorded in all, including the westernmost record of Asiatic golden cat Catopuma temminckii.

On 11 November 2018 at 8:01 a.m., a camera at 4,100 m altitude, $5 \mathrm{~km}$ south-west of Lapchi Village, recorded three 


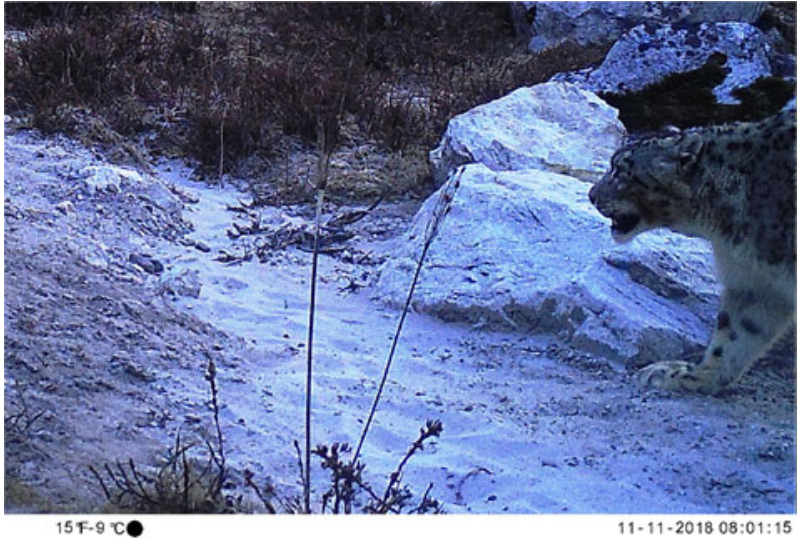

Plate 1 Snow leopard photo-trapped in Gaurishankar Conservation Area (Fig. 1).

photographs of a snow leopard, the first photographic evidence of the presence of the snow leopard in Lapchi Village and the Lamabagar corridor (Plate 1). Whether this snow leopard was a seasonal visitor or has a permanent home range in the area will require further study. The camera that captured the snow leopard recorded four other mammalian species: musk deer, blue sheep, red fox Vulpes vulpes and bobak marmot Marmota bobak.

During fieldwork we also spoke with villagers and herders, and lamas in the monastery, about any conflict with wildlife and about mammalian diversity. None of the herders or villagers reported snow leopards in this area, but the oldest lama in the monastery shared a memory of seeing a snow leopard a long time ago near the village. Villagers reported they are facing threats from the Himalayan black bear Ursus thibetanus laniger, and the head office of Gaurishankar Conservation Area informed us that there were 16 incidents of wildlife attacks against people or livestock in this area in 2018, all reportedly by bears.

Lapchi Village comprises 33 households, all semi-nomadic pastoralists following traditional practices, rearing domestic yak as their livelihood, under a shifting grazing system. All are Sherpa people who follow the Beyul culture of Nyingmapa Buddhism, which emphasizes the sanctity of a landscape of sacred valleys (beyul). These beliefs may have provided protection for the wildlife and habitats of the region. Gaurishankar Conservation Area is being opened for tourists, with a home-stay policy to attract tourists as an alternative livelihood for local economic development. Two mega-hydropower projects are being planned, and the Government of Nepal is planning to open a road link across the border between Nepal and China, through Lapchi village.

Anthropogenic pressure is a major challenge for conservation of the snow leopard and could intensify negative interactions with people (Bagchi \& Mishra, 2006; Jackson et al., 2010; Li et al., 2013; Aryal et al., 2014; Sharma et al., 2015). The rich biodiversity of Lapchi Village, with musk deer, Himalayan tahr, blue sheep, Himalayan brown bear Ursus arctos isabellinus and snow leopard, may attract illegal hunting. Poaching and illegal trade (Li \& Lu, 2014), combined with climate change (Forrest et al., 2012), are major threats to biodiversity in the Himalayas. There are thus both conventional threats and new challenges, but also opportunities to conserve the snow leopard. Spatial analysis of habitats (MoFSC, 2017) suggests that Tamakoshi River is a barrier to movement of snow leopards in Gaurishankar Conservation Area. The corridor in Lamabagar and Alampu links snow leopard habitat to the Quomolongma National Park in China, and may not be greatly affected by climate change under three emission scenarios (Forrest et al., 2017). Lapchi Village could therefore be an important climate change refugium for the snow leopard. A transboundary conservation strategy for conservation of the snow leopard in this region is warranted, with active participation of Nepal, China and international agencies.

Acknowledgements This study was a part of biodiversity research and monitoring programme run by Gaurishankar Conservation Area Project and the National Trust for Nature Conservation. We thank Gaurishankar Conservation Area Project for support, and for permission to conduct the survey and publish the findings.

Author contributions Study design, fieldwork: NPK, BB, BPP, ST, SNS; data analysis, writing: NPK, BB, WVB.

\section{Conflicts of interest None.}

Ethical standards This research involved a non-invasive survey and otherwise abided by the Oryx guidelines on ethical standards.

\section{References}

Ale, S., Thapa, K., Jackson, R. \& Smith, J.D. (2010) The fate of snow leopards in and around Mt. Everest. Cat News, 53, 19-21.

Aryal, A., Brunton, D., Ji, W., Barraclough, R.K. \&

Raubenheimer, D. (2014) Human-carnivore conflict: ecological and economical sustainability of predation on livestock by snow leopard and other carnivores in the Himalaya. Sustainability Science, 9, 321-329.

BagChI, S. \& Mishra, C. (2006) Living with large carnivores: predation on livestock by the snow leopard (Uncia uncia). Journal of Zoology, 268, 217-224.

Forrest, J.L., Wikramanayake, E., Shrestha, R., Areendran, G., Gyeltshen, K., Maheshwari, A. et al. (2012) Conservation and climate change: assessing the vulnerability of snow leopard habitat to treeline shift in the Himalaya. Biological Conservation, 150, 129-135.

Forrest, J.L., Shrestha, R., Sindrof, N. \& Barlett, R. (2017) Landscape Analysis and Mapping of Snow Leopard Habitat in the Eastern Conservation Landscape, Nepal (EHL/N). WWF/USAID, Kathmandu, Nepal.

Green, M.J. (1988) Protected areas and snow leopards: their distribution and status. In Proceedings of the Fifth International Snow Leopard Symposium. International Snow Leopard Trust and Wildife Institute of India, Seattle, Washington (ed. H. Freeman), pp. 3-19. International Snow Leopard Trust, Seattle, USA, \& Wildlife Institute of India, Dehradun, India. 
JACKSON, R. (1979a) Aboriginal hunting in West Nepal with reference to musk deer Moschus moschiferus moschiferus and snow leopard Panthera uncia. Biological Conservation, 16, 63-72.

JACKSON, R. (1979b) Snow leopards in Nepal. Oryx, 15, 191-195.

Jackson, R.M., Mishra, C., McCarthy, T.M. \& Ale, S.B. (2010) Snow leopards: conflict and conservation. In The Biology and Conservation of Wild Felids (eds D.W. Macdonald \& A.J. Loveridge), pp. 417-430, Oxford University Press, Oxford, UK.

Khanal, G., Poudyal, L.P., Devkota, B.P., Ranabhat, R. \& Wegge, P. (2020) Status and conservation of the snow leopard Panthera uncia in Api Nampa Conservation Area, Nepal. Oryx, 54, 421-428.

Kyes, R.C. \& Chalise, M.K. (2005) Assessing the Status of the Snow Leopard Population in Langtang National Park, Nepal. Final Project Report, International Snow Leopard Trust, Seattle, USA.

LI, J. \& LU, Z. (2014) Snow leopard poaching and trade in China 20oo2013. Biological Conservation, 176, 207-211.

Li, J., YIN, H., WANG, D., JiAGONG, Z. \& Lu, Z. (2013) Human-snow leopard conflicts in the Sanjiangyuan Region of the Tibetan Plateau. Biological Conservation, 166, 118-123.
McCarthy, T.M. \& Chapron, G. (2003) Snow Leopard Survival Strategy. Vol. 105. International Snow Leopard Trust and Snow Leopard Network, Seattle, USA.

McCarthy, T., Mallon, D., Jackson, R., Zahler, P. \& McCarthy, K. (2017) Panthera uncia. In The IUCN Red List of Threatened Species 2017: e.T22732A50664030. dx.doi.org/10.2305/ IUCN.UK.2017-2.RLTS.T22732A50664030.en [accessed 22 May 2019]. MoFSC (2017) Snow Leopard and Ecosystem Management Plan (20172026). Ministry of Forest and Soil Conservation, Kathmandu, Nepal.

NTNC (2013) Gaurishankar Conservation Area-Management Plan (2013-2017). National Trust for Nature Conservation, Gaurishankar Conservation Area Project, Dolakha, Nepal.

Sharma, R.K., Bhatnagar, Y.V. \& Mishra, C. (2015) Does livestock benefit or harm snow leopards? Biological Conservation, 190, 8-13.

Sindorf, N. (2017) Eastern Nepal Landscape Water Resources and Climate Change Sensitivity Analysis: High Asia Mountain Initiative. WWF-US, Washington, DC, USA.

WWF (2012) Altai-Sayan Ecoregion Conservation Strategy. WWF, Gland, Switzerland.

WW F (2018) Snow Leopard. wwfnepal.org/what_we_do/wildlife/snow_ leopard [accessed 21 May 2019]. 